\title{
Value relevance do nível de evidenciação do ativo intangível nas companhias de capital aberto brasileiras
}

\author{
Value relevance of the level of disclosure of intangible assets in Brazilian public \\ companies
}

Value relevance del nivel de evidencia del activo intangible en las compañías de capital abierto brasileñas

\section{Juliane Pacheco}

Mestra em Contabilidade pelo Programa de Pós-Graduação em Contabilidade na Universidade Federal de Santa Catarina (UFSC)

Endereço: Rua Geraldo Jansen, n॰ 75, Bairro Ponte do Imarium

CEP: 88130-425 - Palhoça/SC - Brasil

E-mail:pac.juliane@gmail.com

Telefone: (48) 98826-4799

\section{Suliani Rover}

Doutora em Controladoria e Contabilidade pela Universidade de São Paulo (USP)

Professora do Departamento de Ciências Contábeis e do Programa de Pós-Graduação em

Contabilidade da Universidade Federal de Santa Catarina (UFSC)

Endereço: R. Eng. Agronômico Andrei Cristian Ferreira, s/n, Trindade

CEP: 88040-900 - Florianópolis/SC - Brasil

E-mail: sulianirover@gmail.com

Telefone: (48) 3721.3892

\section{Ernesto Fernando Rodrigues Vicente}

Doutor em Administração na Universidade de São Paulo (USP)

Professor do Departamento de Ciências Contábeis e do Programa de Pós-Graduação em Contabilidade da Universidade Federal de Santa Catarina (UFSC)

Endereço: Rua Ferreira Lima, n॰ 107 - Apto. 1101 - Bairro Centro

CEP: 88015-420 - Florianópolis/SC - Brasil

E-mail: ernesto.vicente@ufsc.br

Telefone: (48) 99616.9853

Artigo recebido em 19/02/2018. Revisado por pares em 22/08/2018. Reformulado em 21/09/2018. Recomendado para publicação em 25/02/2019 por Carlos Eduardo Facin Lavarda (Editor-Chefe). Publicado em 10/04/2019. 


\section{Resumo}

Este trabalho teve como objetivo verificar a influência do nível de evidenciação do ativo intangível (NEAI) na value relevance de companhias de capital aberto brasileiras. A amostra de pesquisa é composta por 75 companhias de capital aberto com intangível superior a zero que compõem a carteira de maio a agosto de 2017 do ÍBRx100 na B3. Para mensurar o nível de evidenciação do ativo intangível foi elaborada uma métrica a partir da NBC TG 04 R4 (2017), composta por 14 itens, enquanto a relação entre o NEAI e a value relevance foi feita mediante regressão múltipla. A coleta de dados ocorreu por meio das notas explicativas integrantes das DFP anuais consolidadas de 2016. Os resultados apontaram um nível de evidenciação médio de $62,93 \%$, sendo discrepante a diferença entre o maior e o menor $(91,09 \%)$. Em relação à influência do NEAI na value relevance resultou significativa estatisticamente, com um poder explicativo de $38,09 \%$.

Palavras-chave: Ativo intangível; Value relevance; Evidenciação

\section{Abstract}

This paper aimed to verify the influence of the level of disclosure of the intangible asset in the value relevance of Brazilian public companies. The research sample is composed of the publicly traded companies with intangible assets above zero that compose the portfolio from May to August 2017 of the ÍBRx100 in B3, totaling a sample of 75 companies. To measure the level of disclosure of the intangible asset, a metric was elaborated from CPC 04 R1 (2010), composed of 14 items, while the relationship was made through multiple regression. Data were collected through the explanatory notes included in the consolidated annual Financial Accounting Statements for 2016. The results showed an average disclosure level of $62.93 \%$, the difference between the largest and smallest was 90,91\%. In relation to the influence of the intangible asset in the value relevance was statistically significant, with an explanatory power of $38.09 \%$.

Keywords: Intangible assets; Value relevance; Disclosure

\section{Resumen}

Este trabajo tuvo como objetivo verificar la influencia del nivel de evidencia del activo intangible en el valor de las compañias de capital abierto brasileñas. La muestra de investigación está compuesta por las compañias de capital abierto con intangible superior a cero que componen la cartera de mayo a agosto de 2017 del ÍBRx100 en la B3, totalizando una muestra de 75 empresas. Para medir el nivel de evidencia del activo intangible se elaboró una métrica a partir del CPC 04 RI (2010), compuesta por 14 items, mientras que la relación fue hecha a través de regresión múltiple. La colección de datos ocorrido por medio de las notas explicativas integrantes de los estados financieros consolidadas de 2016. Los resultados demostraron un nivel de evidencia promedio del 62,93\%, siendo discrepante la diferencia entre el mayor y el menor (90,91\%). En cuanto a la influencia del activo intangible en la valoración resultó significativa estadísticamente, con un poder explicativo del 38,09\%.

Palabras clave: Activos intangibles; Value relevance; Divulgación

\section{Introdução}

A Brasil, Bolsa, Balcão (B3) é uma das maiores bolsas de valores da América Latina e atualmente oferece produtos e serviços como negociação de ações, títulos de renda fixa, câmbio pronto, entre outros (FIGO, 2016).

Uma empresa ao desejar, por exemplo, capturar recursos para promover o desenvolvimento de projetos e consequentemente seu crescimento ou obter uma maior visibilidade da empresa, insere suas ações na bolsa de valores (BM\&FBOVESPA, 2016), com 
isso o ambiente empresarial se apresenta mais competitivo e dinâmico, fazendo com que as informações sejam mais tempestivas e confiáveis aos investidores, inclusive para diminuir a assimetria informacional (REZENDE; ALMEIDA; LEMES, 2015).

Assim quanto melhor a evidenciação contábil, melhor será suprida a necessidade do investidor, diminuindo assim a desconfiança gerada por resultados contrários aos anos anteriores e tornando-os dispostos a pagar o preço requerido na ação (REZENDE et al., 2015).

Uma melhor evidenciação diminui a diferença do acesso à informação entre os usuários da contabilidade, uma das características da informação contábil é a relevância, que segundo o Comitê de Pronunciamentos Contábeis (CPC) - Estrutura Conceitual para Elaboração e Divulgação de Relatório Contábil-Financeiro (CPC 00 R1, 2011) é a informação capaz de fazer diferença nas decisões tomadas pelos usuários. Na literatura os estudos para verificar essa relevância das informações contábeis são denominados de value relevance.

O valor de mercado de uma companhia pode ser associado, portanto, as informações, que devem reportar os efeitos de transações e condições que modificaram da entidade e devem ser úteis para tomada de decisão (CPC 00 R1, 2011). A informação, de acordo com a Teoria dos Mercados Eficientes, assim que divulgada incorpora de forma imediata o preço das ações, assim a informação quando relevante permite que o preço das ações seja melhor estimado, melhorando assim seu valor patrimonial (MALKIEL; FAMA, 1970).

Estudos sobre value relevance mostram a relevância e a confiabilidade da informação contábil, ou seja, a forma como a informação impacta o preço da ação (BARTH; BEAVER; LANDSMAN, 2001; LOPES; IUDÍCIBUS, 2004).

Segundo Miguel (2011), uma companhia possui um valor patrimonial maior do que o expresso no balanço patrimonial, visto que muitas vezes possui uma marca forte, uma carteira de clientes sólida ou desenvolve tecnologias inovadoras que nem sempre estão evidenciadas no intangível, mas são fundamentais na hora de calcular o preço da companhia diante dos investidores.

Conforme Meneses, Ponte e Mapurunga (2013), os órgãos reguladores passaram a se preocupar em tornar mais evidente o registro de intangíveis, devido ao seu volume nas empresas, resultando na Deliberação no 488 da Comissão de Valores Mobiliários (CVM) que remodelou a estrutura das demonstrações contábeis das companhias abertas. Os autores supraditos ainda ressaltam a complexidade de identificar e mensurar os ativos intangíveis.

A value relevance do ativo intangível foi analisada anteriormente em alguns países, são eles: Nigéria (ABUBAKAR; ABUBAKAR, 2015), Portugal (OLIVEIRA; RODRIGUES; CRAIG, 2010), França (KIMOUCHE; ROUABHI, 2016), Austrália (JI; LU, 2014) e Irã (GHAHRAMANIZADY; BEHNAME, 2013). No Brasil foi foco nos estudos de Ferreira et al. (2017) e Silva, Souza e Klann (2017), na qual o primeiro verificou a relevância dos contratos de concessão nas empresas do setor de energia elétrica e o segundo analisou a criação de valor dos ativos intangíveis em empresas. Estes estudos, tantos nacionais como internacionais, estudaram o valor do ativo intangível e como ele impacta o preço das ações ou valor de mercado. Porém, nenhum analisou o nível de evidenciação, sendo portanto o diferencial dessa pesquisa, pois estuda a influência no preço das ações do nível de evidenciação do ativo intangível, de acordo com a Norma Brasileira de Contabilidade Técnica Geral (NBC TG) 04 R4 - Ativo Intangível (2017), que define o tratamento contábil dos ativos intangíveis.

Portanto, a pesquisa tem como tema o nível de evidenciação dos intangíveis e a influência que ele exerce no preço das ações praticado na bolsa de valores B3. A intenção desta pesquisa é fornecer evidências sobre a maneira que as companhias abertas estão evidenciando as informações concernentes ao ativo intangível, bem como demonstrar se o nível de evidenciação dessas informações é estatisticamente significativo para explicar o preço da ação das companhias.

Portanto, questiona-se: qual a influência do nível de evidenciação do ativo intangível 


\section{na value relevance das companhias listadas na bolsa de valores $\mathrm{B3}$ ?}

O objetivo geral desta pesquisa é verificar a influência do nível de evidenciação do ativo intangível na value relevance de companhias de capital aberto brasileiras. Para atingir o objetivo proposto, os seguintes objetivos específicos serão perseguidos: (i) mensurar o nível de evidenciação dos ativos intangíveis; (ii) descrever o nível de evidenciação dos ativos intangíveis nas companhias de capital aberto listadas na bolsa de valores brasileira; e (iii) verificar se há relação entre o nível de evidenciação dos ativos intangíveis e o preço das ações nas companhias de capital aberto brasileiras.

A pesquisa se justifica pelo fato de o objetivo principal da contabilidade ser alcançado quando seus relatórios permitirem que cada grupo de usuários possam fazer inferências sobre sua situação econômica e/ou financeira (CPC 00 R1, 2011). Em consonância com Ritta (2010) que afirma que a relevância dos ativos intangíveis tem crescido nas últimas décadas, faz-se necessário analisar se o nível de evidenciação do ativo intangível possui relação com o preço das ações.

Diante o exposto, os intangíveis são essenciais para cálculo do valor de mercado, mesmo quando não estão registrados no ativo. Além disso, os estudos sobre value relevance não contemplaram o nível de evidenciação deste item, portanto, faz-se necessário preencher essa lacuna. Ademais o estudo contribui para o debate sobre a evidenciação dos ativos intangíveis, visto que as empresas podem utilizar diversas maneiras para divulgar suas informações, mas precisam possuir o interesse para divulgá-las.

\section{Fundamentação Teórica e Empírica}

A referida fundamentação teórica está divida em ativo intangível, evidenciação contábil e a trajetória dos estudos de value relevance.

\subsection{Ativo Intangível}

Conforme o CPC 00 R1 (2011), ativo é um recurso controlado pela entidade como resultado de eventos passados e do qual se espera que fluam futuros benefícios econômicos para a entidade.

Perez e Famá (2006) concluem que um recurso físico ou não que está sob o controle da entidade e é utilizado para produzir produtos ou serviços aos seus clientes, gerando assim benefícios econômicos futuros e os custos são representados pelos gastos incorridos para aquisição ou desenvolvimento é um ativo. Ao entender que um ativo é um recurso físico ou não, os autores qualificam um ativo em tangível e intangível.

O tangível é quando o bem ou direito pode ser facilmente identificado e contabilmente separado. Já o intangível é um ativo não monetário identificável sem substância física. Alguns exemplos são: marcas, patentes, direitos autorais (CPC 04 R1, 2010).

Hendriksen e Breda (2009) definem ativos intangíveis como "ativos que carecem de substância" e que para serem reconhecidos devem preencher os requisitos de reconhecimento de qualquer ativo. Os critérios para reconhecimento são: a capacidade de proporcionar benefícios econômicos futuros que serão gerados em favor da entidade e o custo desse ativo puder ser reconhecido com confiabilidade (CPC 04 R1, 2010).

Um ativo satisfaz o critério de identificação de ativo intangível quando for separável e puder ser vendido, transferido, licenciado, alugado ou trocado independente da intenção de uso pela entidade; ou ser resultado de direitos contratuais ou legais (CPC 04 R1, 2010).

Como dito anteriormente, um ativo intangível pode ser tanto advindo de uma compra, transferência, aluguel, dentre outros, como também pode ser gerado internamente. Porém, para ser gerado internamente o reconhecimento é mais difícil em virtude de identificar quando gerará 
benefícios econômicos; e da confiabilidade do custo (CPC 04 R1, 2010).

Assim, pode-se conceituar ativo intangível como bem e/ou direito sem substância física na qual a entidade possua controle e dele se espera benefícios econômicos futuros.

\subsection{Evidenciação Contábil}

O relatório contábil-financeiro, conforme o CPC 00 R1 (2011), fornece informações que são úteis aos investidores, credores e outros usuários das informações. Malacrida e Yamamoto (2006) complementam que a divulgação de informações é fundamental, sendo que se for clara, objetiva e completa transmite uma confiabilidade maior. Lambert, Leuz e Verrecchia (2007) ressaltam que a divulgação afeta a decisão de investidores e credores, bem como pode promover ações nos concorrentes e/ou órgãos reguladores.

Para Marston e Shrives (1991), as empresas possuem diversas maneiras de divulgar suas informações, seja por meio de relatórios trimestrais e/ou semestrais, seja por anúncios na bolsa de valores, ou ainda, por meio informal, como jornais. Independente da forma ou método utilizados na evidenciação, o importante é que o divulgado esteja de acordo com os interesses de cada usuário, a fim de ajudá-los no processo da tomada de decisão (KLANN; BEUREN, 2010).

Admitindo que a credibilidade seja o foco central para uma divulgação eficaz, Gibbins, Richardson e Waterhouse (1990) afirmam que a credibilidade pode ser consolidada com o tempo, por meio tanto das políticas internas, como das regras de divulgação das empresas. Healy e Papelu (2001) acreditam que o funcionamento de um mercado de capitais eficiente é fundamentado pela divulgação, reduzindo assim a assimetria informacional entre gestores e investidores. Complementado por Meneses, Ponte e Mapurunga (2013, p.4) que fazer uma divulgação adequada para atender a todos os usuários pode ser justificada pela redução da assimetria informacional, proporcionando uma "redução dos custos de capital e maior credibilidade dos gestores, e o aumento do valor da empresa".

Ao aumentar a qualidade da divulgação obrigatória, pode reduzir a taxa de risco da empresa (LAMBERT; LEUZ; VERRECCHIA, 2007). Além disso, um alto nível de evidenciação repercute positivamente, acarretando uma melhor avaliação financeira, como maior retorno, menor custo de captação e menor flutuação do preço das ações (MALACRIDA; YAMAMOTO, 2006).

Schvirck, Lunkes e Gasparetto (2013, p.134) sustentam que "os órgãos reguladores do mercado, e também os investidores e financiadores, buscam melhorar a evidenciação de informações das companhias". Visto que a entidade que possui maior transparência da evidenciação recebe mais recursos dos investidores e financiadores. Porém, uma informação não pode estar apenas atrelada ao valor numérico, de forma quantitativa, mas também deve vir acompanhada por uma explicação, algo qualitativo que fará com que aquele número seja útil aos usuários da informação (MARSTON; SHRIVES, 1991),

A Teoria da Divulgação tratada por Verrecchia (1983) como aquela que as informações a serem divulgadas vão de acordo com a vontade de divulgação do gestor, nem sempre sendo neutro, ficando ainda no seu julgamento a qualidade e a quantidade a ser divulgada. Gibbins, Richardson e Waterhouse (1990) enfatizam que o tamanho da empresa, o desempenho financeiro e a personalidade e preferência de um CEO influenciam a divulgação. Por isso, segundo Ritta (2010) a informação contábil deve ser útil, precisa e relevante para seus diversos usuários, permitindo uma análise do desempenho organizacional.

Relacionando a Teoria da Divulgação baseada na associação, conforme Verrecchia (2001), que investiga o efeito da evidenciação exógena sobre as ações dos investidores, a assimetria informacional e a necessidade dos usuários por informação com o intangível das empresas, é necessário que taxas, vida útil, amortização, exaustão, perda de recuperabilidade, 
dentre outros sejam evidenciados para o investidor ter conhecimento do patrimônio incorpóreo da entidade.

Inclusive, como não se pode registrar um ativo gerado internamente, as empresas fazem uso das notas explicativas para evidenciar potenciais interessados nas suas informações contábeis (FERNANDES; SALUSSE; JABOUR, 2014), tornando essencial a evidenciação contábil. Além de que, empresas com alto nível de evidenciação podem transmitir aos investidores uma confiança que resulta num preço da ação justo.

\subsection{Value Relevance: trajetória e estudos anteriores}

Durante a década de 60, conhecida por "Era de Ouro", os estudos desenvolvidos eram mais voltados à teoria positivista, na qual a teoria é correta desde que for comprovada por métodos científicos válidos (BALL; BROWN, 2013). O estudo de Ball e Brown (1968) foi um dos pioneiros em verificar o quão útil à informação do resultado é para influenciar o preço da ação.

Além dos autores supracitados, Beaver (1968) também buscou enfatizar essa influência. Ambos destacaram que não é apenas o momento da divulgação dos relatórios (lucros) que interfere no mercado, mas após a sua divulgação também há uma tendência.

Os estudos que consideram se a informação impacta sobre o preço da ação são denominados de value relevance, sendo que se impactante é porque essa informação é relevante para o mercado.

Os estudos de value relevance podem ser abordados por três categorias, segundo Holthausen e Watts (2001): (i) associação incremental, onde o modelo de avaliação é útil para explicar o valor da ação, e afirma que as diferenças entre os valores estimados e previstos são geralmente interpretadas como evidências de erro de mensuração nos números contábeis; (ii) conteúdo informacional marginal, em que a variação do valor da ação está associada à divulgação das informações contábeis, normalmente utilizada pelos estudos de eventos; e (iii) associação relativa, na qual compara o preço da ação e os valores contábeis de acordo com as normas, seu teste é de acordo com o coeficiente de determinação $\left(\mathrm{R}^{2}\right)$.

Esses estudos possuem objetivos específicos e hipóteses alternativas que mostram a relevância e confiabilidade dos números contábeis (BARTH; BEAVER; LANDSMAN, 2001).

Corroborando os autores supracitados, Lopes e Iudícibus (2004) afirmam que os estudos sobre value relevance buscam verificar os aspectos relacionados ao conteúdo informacional das demonstrações contábeis para o mercado de capitais, visto que o preço das ações se ajusta em função dessas informações.

Hassan e Mohd-Saleh (2010) verificaram a value relevance nos instrumentos financeiros em 203 companhias da Malásia nos anos de 1999, 2000, 2002 e 2003. Além disso, também verificaram o nível de divulgação dos instrumentos financeiros, visto que em 2001 foi aderida a norma MASB 24 - Financial Instruments: Disclosure and Presentation, a média foi de $33,49 \%$, sendo o mínimo de 3,57\% e o máximo de $97,14 \%$. Em relação ao value relevance, os autores viram a qualidade de divulgação dos instrumentos financeiros como um fator importante para o valor de mercado, porém após a adoção, um poder explicativo menor foi encontrado. Por fim, que o valor relevante para o mercado é o valor justo, indicando que os investidores consideram as informações a valor justo e a qualidade da divulgação no momento de decisão.

Estudos de value relevance do ativo intangível foram encontrados em: Turquia, Nigéria, Portugal, França, Áustria e Irã. Ozer e Çam (2016) analisaram empresas industriais de Istambul publicamente negociáveis e verificaram que o capital intelectual pode explicar a diferença entre o valor de mercado e o valor contábil, afetando assim o desempenho da empresa, no período de 2004 a 2014. O capital humano revelou que impacta significativamente na variação dos valores 
das empresas turcas, sendo que sua divulgação através de indicadores possui influência para tomada de decisão de avaliação de negócio.

Oliveira, Rodrigues e Craig (2010) avaliaram a relevância do valor dos ativos intangíveis identificados e do goodwill reportados nas demonstrações contábeis cotadas no mercado da bolsa de valores de Portugal de 1998 a 2008. No país houve, após a adoção da IFRS 3 e IAS 38 em 2005, distinção em como reconhecer os intangíveis, por exemplo gastos com pesquisa e desenvolvimento e não amortizar mais o goodwill. A referida pesquisa mostrou que o lucro líquido, ágio e outros ativos intangíveis estão altamente associados ao preço da ação, visto que eles eram maiores antes da adoção da IFRS, porém não houve um impacto como um todo, dado que em relação ao goodwill houve um efeito positivo.

Ghahramanizady e Behname (2013) afirmam que todos os ativos intangíveis, sejam comprados ou produzidos pela empresa, devem ser identificados e relatados nas demonstrações. Os autores trazem também a associação anteriormente citada da relação entre o valor de mercado e os números contábeis como uma value relevance e confiabilidade das demonstrações contábeis.

Em um estudo sobre os ativos relatados nas demonstrações e o valor de mercado das empresas da Tehran Stock Exchange (TSE, maior bolsa de valores do Irã), encontrou-se uma relação significativa, os ativos intangíveis reconhecidos são de valor relevante para explicar o valor patrimonial de mercado na indústria de metais do TSE no período de 2001 a 2011 (GHAHRAMANIZADY; BEHNAME, 2013).

Já nas empresas de alta tecnologia da Nigéria, foi feito um estudo no período de 2005 a 2011 por Abubakar e Abubakar (2015), na qual afirmam que elas operam com ativos intangíveis nem sempre reconhecidos pela contabilidade, e que os reguladores devem criar uma norma para que as empresas possam registrar suas marcas. Os autores apoiam-se no sentido de que o ativo da marca é relevante e confiável, ou seja, as duas principais características qualitativas de informação contábil financeira, visto que no referido estudo há relevância conjunta do valor incremental do reconhecimento do ativo intangível (marca) no balanço das empresas e que há confiabilidade das empresas no reconhecimento do mesmo.

A convergência da norma internacional, estudada por Ji e Lu (2014) durante os anos de 2000 a 2009 em empresas da Austrália com goodwill ou outro intangível, concluiu que as empresas mudaram de comportamento em relatar os intangíveis, visto que como citado anteriormente, não precisavam mais amortizar o goodwill entre 5 a 20 anos. Essa mudança no comportamento foi devido aos requisitos mais rigorosos para o reconhecimento do intangível; marcas, pesquisa e desenvolvimento, ágio interno não foram mais contabilizados no balanço patrimonial, o que acabou contribuindo para o declínio da relevância do valor do intangível capitalizado após o período da adoção, mesmo a pesquisa resultando numa associação positiva entre o valor de mercado de ações e os valores contábeis de ativos intangíveis capitalizados, sendo que a confiabilidade não mudou após a adoção.

Por fim, Kimouche e Rouabhi (2016) analisaram empresas francesas cotadas na bolsa da União Europeia de 2005 a 2013, para verificar se o ativo intangível como um todo e o fluxo de caixa possuem value relevance. Os autores concluíram que a amortização e o teste de impairment dos intangíveis e os fluxos de caixa não afetam os valores de mercado, ao contrário de outros intangíveis que afetaram positivamente e substancialmente o valor de mercado, como no caso do ágio comparado ao ativo interno. Evidenciaram também que o intangível melhora a relevância do valor das informações contábeis.

Em estudos brasileiros, Macedo, Machado e Machado (2013), Gonçalves et al. (2014) e Santos, Starosky e Klann (2014) verificaram se houve relação entre o Lucro Líquido por ação e/ou o Patrimônio Líquido por ação das empresas não financeiras da Bolsa de Valores de São Paulo. O primeiro analisou o período de 1997 a 2009, dividindo o período em pré e pósconvergência das normas, sendo verificada uma diferença entre eles nessa transição; enquanto 
o lucro líquido por ação representou um ganho de relevância, o patrimônio líquido por ação apresentou uma perda no seu conteúdo informacional. Cabe registrar também que em 2008 houve uma crise que pode ter afetado o patrimônio líquido por ação, visto que por não ser tão volátil acabou não acompanhando o preço da ação.

Gonçalves et al. (2014) também verificaram se o processo de internacionalização da contabilidade impactou a relevância das informações contábeis de lucro líquido por ação e patrimônio líquido por ação no período de 2009 e 2010. Os resultados apontaram um impacto positivo estatisticamente, sendo que em 2010 o preço das ações foi melhor explicado que em 2009, trazendo ganhos de relevância o processo de convergência.

Ainda analisando o efeito do processo de convergência internacional, Santos, Starosky e Klann (2014) analisaram os anos de 2006 a 2011 e tomaram como base o preço da ação em vários períodos. Os autores concluíram que há evidências estatísticas sobre o efeito do processo de convergência na value relevance das demonstrações contábeis das empresas brasileiras pesquisadas, principalmente em relação ao poder explicativo do valor patrimonial da ação e o lucro por ação sobre o valor de mercado da ação seis meses após o encerramento do exercício. Ao relacionar com o preço final do exercício o mesmo efeito não é observado.

Entrando em itens do balanço patrimonial, Martins, Machado e Callado (2014) avaliaram os ativos biológicos ao valor justo, durante o último trimestre de 2010, os quatro trimestres de 2011 e o primeiro de 2012 das companhias de capital aberto não financeiras da BM\&FBovespa que atuam na exploração de atividades agrícolas. Os resultados apontaram uma significância estatística na determinação do valor de mercado tanto dos ativos biológicos a curto prazo como a longo prazo, visto que são relevantes, sua mensuração ao valor justo mostrou-se confiável.

Pinto et al. (2014) avaliaram outro item no balanço patrimonial, evidenciaram se as provisões e passivos contingentes estão relacionados ao valor de mercado das 65 companhias do Índice Ibovespa de 2010, nos anos de 2010 a 2013, resultando em 268 observações na qual constataram que quanto maior o valor de mercado, menor o nível de evidenciação das provisões e ativos e passivos contingentes. Verificaram ainda que essa evidenciação não é relevante para investidores no processo de tomada de decisão. Por fim, verificaram que quanto maior o lucro por ação, maior o endividamento e a provisão por ação e quanto maior a probabilidade da empresa em divulgar as informações sobre contingencias o nível de evidenciação está acima do setor de atuação. Informaram ainda que o nível de evidenciação obrigatória de provisões e passivos contingente, segundo o CPC 25 - Provisões, Passivos Contingentes e Ativos Contingentes, foi de $54,2 \%$.

Estudos sobre value relevance do ativo intangível em companhias brasileiras foram estudadas por Silva, Souza e Klann (2017) na qual analisou a influência dos ativos intangíveis na relevância da informação contábil e os resultados apontaram ativo intangível e goodwill, juntamente com patrimônio líquido e lucro líquido (ambos também ajustados) são informações relevantes para o mercado de capitais e impactam no preço das ações até seis meses depois de publicadas as demonstrações financeiras.

Já Ferreira et al. (2017) verificaram a relevância dos contratos de concessão no comportamento dos preços das ações das empresas de energia elétrica no Brasil. Apesar do lucro, o patrimônio líquido e os contratos de concessão serem relevantes, apresentaram um poder incremental dos contratos de concessão quase nulo.

Em relação ao a value relevance do nível de evidenciação das combinações de negócio e o goodwill, Souza e Borba (2017) verificaram que as combinações de negócios tendem a valorizar a ação quando o nível de evidenciação é melhor. Já relacionado ao goodwill quando reconhecido na combinação de negócio não é relevante para explicar o preço da ação, podendo estar relacionado com o baixo nível de evidenciação do goodwill. O nível de evidenciação das combinações de negócio dentre as 196 empresas analisadas obteve uma média de 29\%, sendo 
o nível máximo foi de $66 \%$ e o mínimo de apenas $7 \%$.

Os estudos anteriores sobre value relevance, quando pesquisaram sobre o ativo intangível, estavam focados no valor do intangível para o mercado acionário. Já os estudos sobre nível de evidenciação e o preço das ações também não estudaram o intangível, de forma que o presente estudo visa suprir a lacuna existente sobre a associação do nível de evidenciação do ativo intangível em companhias brasileiras e o mercado de ações.

\section{Procedimentos Metodológicos}

Esta seção tem por objetivo apresentar: (i) amostra e coleta de dados e, (ii) procedimentos para coleta de dados dividido em nível de disclosure do ativo intangível e o método da regressão múltipla.

\subsection{Amostra e Coleta de Dados}

A amostra da pesquisa é caracterizada como não probabilística, visto que foi constituída pelas companhias de capital aberto com intangível superior a zero que compõem a carteira de Índice Brasil 100 (IBrX 100) na B3 no ano de 2017, exceto as instituições financeiras, por possuírem particularidades específicas do setor.

Quadro 1 - Empresas pertencentes à carteira IBrX 100 de maio a agosto de 2017

\begin{tabular}{|c|c|c|c|c|c|}
\hline Empresa & & Empresa & & Empresa & \\
\hline AES Tiete Energia S.A. & Sim & Cyrela Brazil Realty S.A. & Sim & Marfrig Global Foods S.A. & Sim \\
\hline Aliansce Shop Centers SA & Não ${ }^{1}$ & Duratex S.A. & Sim & Metalúrgica Gerdau S.A. & Sim \\
\hline Alupar Investimento S.A. & Sim & Ecorodovias Infra. e Log S.A. & Sim & Minerva S.A. & Sim \\
\hline Ambev S.A. & Sim & Energias do Brasil S.A. & Sim & MRV Eng e Particip S.A. & Sim \\
\hline B2W Companhia Digital & Sim & Eletropaulo S.A & Sim & Multiplan Empreend Imob AS & Não \\
\hline B3 - Brasil Bolsa Balcão & $\mathrm{Não}^{1}$ & Embraer S.A. & Sim & Multiplus S.A. & Sim \\
\hline Banco Bradesco S.A. & Não $\mathrm{O}^{1,5}$ & Energisa S/A & Sim & Natura Cosméticos S.A. & Sim \\
\hline Banco do Brasil S.A & $\mathrm{Não}^{1}$ & ENGIE Brasil Energia S.A. & Sim & Odontoprev S.A. & Sim \\
\hline Bco Est Rio Gde do Sul & Não ${ }^{1}$ & Equatorial Energia S.A. & Sim & Petróleo Brasileiro S.A. & Sim \\
\hline Banco Santander (Brasil) & Não ${ }^{1}$ & Estácio Participações S.A. & Sim & Porto Seguro S.A. & Não \\
\hline BB SeguridaParticip S.A & Não ${ }^{1}$ & EZ TEC Emp e Particip S.A. & Sim & QGEP Participações S.A. & Sim \\
\hline BR Malls Particip S.A. & Não $^{1}$ & Fibria Celulose S.A. & Sim & Qualicorp S.A. & $\mathrm{Sim}$ \\
\hline BR Properties S.A. & Não ${ }^{1}$ & Fleury S.A. & Sim & Raia Drogasil S.A. & Sim \\
\hline Bradespar S.A. & $\mathrm{Não}^{2}$ & Gafisa S.A. & Sim & Randon S.A. & Sim \\
\hline Braskem S.A. & $\mathrm{Não}^{3}$ & Gerdau S.A. & Sim & Rumo S.A. & Sim \\
\hline BRF S.A. & Sim & Gol Linhas Aéreas S.A. & Sim & São Martinho S.A. & Não \\
\hline CCR S.A. & Sim & Grendene S.A. & Sim & Ser Educacional S.A. & $\mathrm{Sim}$ \\
\hline Cemig S.A. & Sim & Hypermarcas S.A. & Sim & Smiles S.A. & Sim \\
\hline Centrais Elét Brasileira & $\mathrm{Sim}^{5}$ & Iguatemi Shop Centers S.A & Não & Sul América S.A. & Não \\
\hline Cia. Hering & Sim & Iochpe-Maxion S.A. & Sim & Suzano Papel e Celulose S.A. & Sim \\
\hline Cielo S.A. & Não ${ }^{1}$ & Itaú Unibanco Holding.A. & Não & Telefônica Brasil S.A. & Sim \\
\hline Cia Brasileira de Distrib. & $\mathrm{Sim}$ & Itausa Investimentos Itaú & Não & Tim Participações S.A. & Sim \\
\hline Cia de San. Bsc do Est SP & $\mathrm{Sim}^{4}$ & JBS S.A. & Sim & TOTVS S.A. & Sim \\
\hline Cia de Saneam.de & Sim & Klabin S.A. & Sim & Transmissora Aliança SA & $\mathrm{Sim}$ \\
\hline Cia de Saneam. do Paraná & $\mathrm{Sim}^{4}$ & Kroton Educacional S.A. & Sim & Tupy S.A. & $\mathrm{Sim}$ \\
\hline Cia Tr. Energia El. & Sim & Light S.A. & Sim & Ultrapar Participações S.A. & Sim \\
\hline Cia Energética de SP & $\mathrm{Sim}^{4}$ & Localiza Rent a Car S.A. & Sim & Usinas Siderúrgicas de MG & $\mathrm{Sim}$ \\
\hline Cia Paranaense de Energia & Sim & Lojas Americanas S.A. & Sim & Vale S.A. & Sim \\
\hline Cia Siderúrgica Nacional & Não ${ }^{3}$ & Lojas Renner S.A. & Sim & Valid Soluções e Serviço AS & Sim \\
\hline Cosan S.A. & Sim & M. Dias Branco S. A. & Sim & Via Varejo S.A. & Sim \\
\hline CPFL Energia S.A. & Sim & Magazine Luiza S.A. & Sim & Weg S.A. & Sim \\
\hline
\end{tabular}




\begin{tabular}{|c|c|c|c|c|c|}
\hline Empresa & & Empresa & & Empresa & \\
\hline AES Tiete Energia S.A. & Sim & Cyrela Brazil Realty S.A. & Sim & Marfrig Global Foods S.A. & Sim \\
\hline Aliansce Shop Centers SA & Não ${ }^{1}$ & Duratex S.A. & Sim & Metalúrgica Gerdau S.A. & Sim \\
\hline Alupar Investimento S.A. & Sim & Ecorodovias Infra. e Log S.A. & Sim & Minerva S.A. & Sim \\
\hline Ambev S.A. & Sim & \begin{tabular}{|l|} 
Energias do Brasil S.A. \\
\end{tabular} & Sim & MRV Eng e Particip S.A. & Sim \\
\hline B2W Companhia Digital & Sim & Eletropaulo S.A & Sim & Multiplan Empreend Imob AS & Não \\
\hline B3 - Brasil Bolsa Balcão & Não ${ }^{1}$ & Embraer S.A. & $\operatorname{Sim}$ & Multiplus S.A. & Sim \\
\hline Banco Bradesco S.A. & Não $0^{1,5}$ & Energisa S/A & Sim & Natura Cosméticos S.A. & Sim \\
\hline Banco do Brasil S.A & Não ${ }^{1}$ & ENGIE Brasil Energia S.A. & Sim & Odontoprev S.A. & Sim \\
\hline Bco Est Rio Gde do Sul & Não ${ }^{1}$ & Equatorial Energia S.A. & Sim & Petróleo Brasileiro S.A. & Sim \\
\hline Banco Santander (Brasil) & Não ${ }^{1}$ & Estácio Participações S.A. & Sim & Porto Seguro S.A. & Não \\
\hline BB SeguridaParticip S.A & Não ${ }^{1}$ & EZ TEC Emp e Particip S.A. & Sim & QGEP Participações S.A. & Sim \\
\hline BR Malls Particip S.A. & Não ${ }^{1}$ & Fibria Celulose S.A. & Sim & Qualicorp S.A. & Sim \\
\hline BR Properties S.A. & Não ${ }^{1}$ & Fleury S.A. & Sim & Raia Drogasil S.A. & Sim \\
\hline Bradespar S.A. & Não ${ }^{2}$ & Gafisa S.A. & Sim & Randon S.A. & Sim \\
\hline Braskem S.A. & Não ${ }^{3}$ & Gerdau S.A. & Sim & Rumo S.A. & Sim \\
\hline BRF S.A. & Sim & Gol Linhas Aéreas S.A. & Sim & São Martinho S.A. & Não \\
\hline CCR S.A. & Sim & Grendene S.A. & Sim & Ser Educacional S.A. & Sim \\
\hline Cemig S.A. & Sim & Hypermarcas S.A. & Sim & Smiles S.A. & Sim \\
\hline Centrais Elét Brasileira & $\operatorname{Sim}^{5}$ & Iguatemi Shop Centers S.A & Não & Sul América S.A. & Não \\
\hline Cia. Hering & Sim & Iochpe-Maxion S.A. & Sim & Suzano Papel e Celulose S.A. & Sim \\
\hline Cielo S.A. & Não ${ }^{1}$ & Itaú Unibanco Holding.A. & Não & Telefônica Brasil S.A. & Sim \\
\hline Cia Brasileira de Distrib. & Sim & Itausa Investimentos Itaú & Não & Tim Participações S.A. & Sim \\
\hline Cia de San. Bsc do Est SP & $\mathrm{Sim}^{4}$ & JBS S.A. & Sim & TOTVS S.A. & Sim \\
\hline CVC Brasil S.A. & Sim & Marcopolo S.A. & Sim & & \\
\hline Total & 19 & Total & 29 & Total & 27 \\
\hline
\end{tabular}

Fonte: elaborada pelas autoras com base na carteira IBrX 100 de maio a agosto de 2017

Legenda: 1 - empresas financeiras; 2 - empresas com ativo intangível igual à zero; 3 - empresas que não divulgaram as demonstrações contábeis padronizadas em 2016; 4 - empresas que apresentaram apenas as demonstrações individuais; 5 - empresas que apresentaram duas ações na carteira IBrX 100 no referido período.

A IBrx 100 possui as 100 ações mais negociadas da bolsa de valores, portanto possui empresas de setores diferentes, além de serem empresas com a maior representatividade no mercado brasileiro. A amostra é composta pelas empresas que participaram da carteira de maio a agosto de 2017, sendo constituída por 95 empresas, visto que cinco empresas apresentaram duas ações na carteira. O Quadro 1 destaca as empresas que compuseram a amostra.

Das 95 empresas, foram excluídas da amostra 20 empresas, sendo 16 por serem do setor financeiro, uma não possuía ativo intangível na sua demonstração consolidada e três por não publicarem as demonstrações financeiras padronizadas de 2016, ano no qual foi analisada a influência do nível de evidenciação do ativo intangível no preço das ações. Destarte, os dados para medir o nível de disclosure dos ativos intangíveis, bem como as informações necessárias para a análise da influência das 75 observações, foram coletados nas demonstrações financeiras padronizadas das empresas publicados no site da B3.

\subsection{Procedimentos de Análise dos Dados}

Nesta subseção elabora-se a coleta de dados da pesquisa, dividida em nível de disclosure do ativo intangível e análise de regressão múltipla.

\subsubsection{Nível de disclosure do ativo intangível}

No presente trabalho, para análise da evidenciação, são abordados os itens que foram extraídos dos itens 118 a 128 da NBC TG 04 R4 (2017) para divulgação. 
Visando medir o nível de evidenciação, foi calculado um índice com base na Equação 1 apresentada a seguir e na análise da evidenciação foi adotada a seguinte metodologia: nos casos em que a respectiva informação encontrava-se nas notas explicativas ou nas próprias demonstrações contábeis da respectiva empresa em análise, atribuiu-se 1 (um ponto) indicando um "sim" presença da informação. Nos casos em que a informação não foi encontrada ou de maneira parcial atribuiu-se 0 (zero) indicando "não evidenciação". Por fim, nos casos em que o item não se aplica, será atribuído "NA" (não se aplica) e será excluído da métrica da referida empresa.

Os itens que compõem a medição do nível de evidenciação estão dispostos no Quadro 2. Em relação à lista de verificação, primeiramente, nota-se a natureza do intangível, visto a peculiaridade de cada empresa como concessão, software, ágio, fundo de comércio, carteiras de clientes. Verificou-se também se a companhia divulga a vida útil definida ou indefinida.

Quadro 2: Lista de itens de verificação
\begin{tabular}{|c|l|}
\hline Número & Item \\
\hline 1 & Natureza do intangível \\
\hline 2 & Informa vida útil \\
\hline 3 & Prazo da vida útil definida \\
\hline 4 & Taxa para amortização \\
\hline 5 & Método de amortização \\
\hline 6 & Valor contábil bruto \\
\hline 7 & Informa amortização acumulada \\
\hline 8 & Efetuou o teste de recuperabilidade \\
\hline 9 & Informou valor da perda (caso houve) \\
\hline 10 & Informou se houve reversão (caso houve) \\
\hline 11 & Evidencia valor perda/reversão na DRE (caso houve) \\
\hline 12 & Evidencia valor amortizado na DRE \\
\hline 13 & Concilia valor inicial e final - baixa e entradas \\
\hline 14 & Evidencia além das exigidas na NBC TG 04 (R4) \\
\hline
\end{tabular}

Fonte: Elaborado com base na NBC TG 04 (R4, 2017).

Caso a entidade tenha algum ativo intangível com a vida útil definida, se informou esse prazo, de forma temporal. Por conseguinte, a taxa individual ou por natureza que esses intangíveis são depreciados. Quanto ao método de amortização deveria estar explícito, caso contrário não pontuou.

Em relação ao valor contábil bruto e a amortização acumulada (itens seis e sete) foi pontuado caso divulgado junto à conciliação desde que explícitas.

O CPC 04 R1 (2010) apoia que seja realizada no findar de cada exercício social uma avaliação para verificar a possibilidade de recuperação, caso se confirme que houve uma redução na capacidade de recuperação, total ou parcial, a empresa poderá registrar uma perda correspondente ao valor não recuperável constatado no ativo. A NBC TG 04 R4 (2017), em seu item 120 solicita a divulgação dos intangíveis que perderam valor recuperável, dessa forma os itens $8,9,10$ e 11 da métrica foram analisados em conjunto.

A análise do teste no valor recuperável foi dividida em duas etapas, na qual foi primeiro observado o item oito, verificando se a empresa evidenciou que foi realizado o teste do valor recuperável e o seu resultado. Caso afirmativo passaria para o item nove, caso negativo não pontuaria nos demais itens. Caso informou no item oito que não houve perda ou reversão os itens nove e dez receberiam um "NA". No que tange ao item nove e dez, seria pontuado caso apresentasse o resultado do teste em valores monetários. Assim como no item 12, que receberia um "NA" caso não houve perda, um se apresentasse o valor na DRE e zero se não evidenciasse.

Em relação ao item 12, evidenciar o valor amortizado na Demonstração do Resultado do Exercício (DRE), considerou-se a DRE do site da B3 e caso alguma empresa apresentou as 
demonstrações novamente nas notas explicativas. Para este item, e o item 11, não foram considerados as informações complementares em nota explicativa com a abertura dos valores da DRE.

Conforme o item 13 da lista de verificação, as empresas devem divulgar a composição do intangível através da conciliação entre o valor inicial e final, bem como as entradas e baixas durante o período.

E por fim, o item 14 refere-se a evidenciar algo além do exigido pela NBC TG 04 R4 (2017), conforme item 128-b, como valores gastos em novos produtos, pesquisas e desenvolvimento de novos projetos, combinações de negócios resultantes em intangível, dentre outros. Os itens foram calculados conforme a Equação 1.

Índice de evidenciação $=$ $\sum$ Quantidade de itens evidenciados

$$
\text { (Quantidade total de quesitos - Itens que não se aplica) }
$$

Para cálculo do nível de evidenciação foram analisadas as notas explicativas relativas às demonstrações financeiras padronizadas consolidadas, sendo que cinco empresas (Cia Energética de São Paulo, Eletropaulo Metropolitana Eletricidade de São Paulo S.A., Multiplus S.A., Cia Saneamento do Paraná e Cia Saneamento Básico do Estado de São Paulo) foram utilizadas as individuais por não serem apresentadas as consolidadas.

\subsubsection{Análise de Regressão Múltipla}

O objetivo da análise de regressão múltipla é prever as mudanças na variável dependente como resposta a mudanças nas variáveis independentes (Hair et al., 2009). Mais especificamente, esse método de análise permite com que várias variáveis (características quantitativas e qualitativas) sejam utilizadas para explicar a variabilidade de uma característica quantitativa de interesse.

Os modelos de regressão são considerados extremamente importantes em trabalhos práticos, pois permitem que se estabeleça uma relação de casualidade entre várias características, ou seja, uma equação que represente o quanto muda uma característica quando variamos outra característica. $\mathrm{O}$ presente estudo buscou verificar a influência do nível de evidenciação do ativo intangível, portanto está relacionado à associação relativa segundo as categorias de Holthausen e Watts (2001).

Sendo a variável dependente a primeira cotação do preço da ação no dia 30 de abril do ano subsequente ao analisado, corroborando Macedo et al. (2013), Batista, Oliveira e Macedo (2017) e Macedo et al. (2011), ao limite de 5 de maio.

Já as variáveis independentes serão o resultado líquido por ação, patrimônio líquido por ação e nível de evidenciação do ativo intangível. As variáveis resultado líquido por ação e patrimônio líquido por ação foram utilizadas como variáveis de controle, conforme o modelo de Ohlson (1995), para evidenciar se ao acrescentar o nível de evidenciação do ativo intangível na função resultará alguma relevância significativa.

A regressão foi dividida em duas etapas. Primeiramente, analisou-se toda a amostra, ou seja, integraram as 75 observações. Posteriormente, utilizou-se a técnica de detecção de outliers multivariados de Hadi (1992), na qual foram excluídas oito observações, e efetuou-se a regressão com 67 observações. Foi utilizado o software Stata e as Equações são apresentadas a seguir para ambas as etapas, com base no modelo de Ohlson (1995):

$$
\begin{aligned}
& \mathrm{P}_{\mathrm{i}}=\alpha_{0}+\alpha_{1} \mathrm{RLAC}+\alpha_{2} \mathrm{PLAC}+\varepsilon \\
& \mathrm{P}_{\mathrm{i}}=\alpha_{0}+\alpha_{1} \mathrm{RLAC}+\alpha_{2} \mathrm{PLAC}+\alpha_{3} \mathrm{NEAI}+\varepsilon_{\mathrm{i}} \\
& \text { Onde: } \\
& \text { P é o preço da ação na primeira cotação }
\end{aligned}
$$


$\alpha_{0}$ é a constante

$\alpha_{1,2,3}$ é o coeficiente de inclinação da variável explicativa

RLAC é o resultado líquido por ação

PLAC é o patrimônio líquido por ação

NEAI é o nível de evidenciação obtido através da métrica da seção 3.3.1

$\varepsilon_{\mathrm{i}}$ é o erro

Os pressupostos da análise de regressão múltipla contemplam: a distribuição normal dos resíduos estimados; a correlação entre os resíduos e cada variável explicativa não pode ser elevada, do mesmo modo que entre as variáveis explicativas também não poderá haver (FÁVERO et al., 2014). Na qual foi realizado os testes de Shapiro-Francia, Breush-Pagan, White e o VIF para verificar se as observações contemplam esses pressupostos.

\section{Análise de Resultados}

A Tabela 1 mostra a média do nível de evidenciação do ativo intangível por setor de atuação das 75 empresas analisadas. Nota-se que os setores de Telecomunicações e Saúde possuem maior média de evidenciação com $77,27 \%$ e $76,05 \%$, respectivamente. As empresas analisadas apresentaram uma média do nível de evidenciação de $62,93 \%$.

Duas empresas apresentaram o menor índice de evidenciação, sendo uma do setor de Consumo Cíclico (EZ TEC Empreendimentos e Participações) e outra de Materiais Básicos (Klabin S.A.) com 9,09\%, que divulgaram apenas um item: realização do teste de recuperabilidade e não houve perda ou reversão, sendo, portanto uma métrica de 11 itens.

Tabela 1 - Média do nível de evidenciação por setor de atuação

\begin{tabular}{l|c|c|c|c|c}
\hline Setor de atuação & Número empresas & Média & Desvio padrão & Máximo & Mínimo \\
\hline Bens Industriais & 10 & 59,00 & 10,25 & 72,73 & 36,36 \\
\hline Consumo Cíclico & 19 & 64,49 & 20,95 & 90,91 & 9,09 \\
\hline Consumo Não Cíclico & 9 & 67,13 & 10,35 & 81,82 & 53,85 \\
\hline Materiais Básicos & 8 & 58,39 & 21,67 & 76,92 & 9,09 \\
\hline Petróleo, Gás e Biocombustíveis & 4 & 64,11 & 16,77 & 84,62 & 45,45 \\
\hline Saúde & 4 & 76,05 & 11,35 & 90,91 & 63,64 \\
\hline Tecnologia da Informação & 1 & 63,64 & - & 63,64 & 63,64 \\
\hline Telecomunicações & 2 & 77,27 & 6,43 & 81,82 & 72,73 \\
\hline Utilidade Pública & 18 & 58,59 & 18,46 & 100,00 & 21,43 \\
\hline Total & $\mathbf{7 5}$ & $\mathbf{6 2 , 9 3}$ & $\mathbf{1 7 , 2 3}$ & $\mathbf{1 0 0 , 0 0}$ & $\mathbf{9 , 0 9}$ \\
\hline Fonte: Elabran
\end{tabular}

Fonte: Elaborado pelos autores com base nos dados da pesquisa.

As duas companhias juntamente com a Transmissora Aliança de Energia Elétrica S.A. não apresentaram nota explicativa relativa ao ativo intangível, sendo que a última obteve um nível de evidenciação de 36,36\% em virtude da nota de principais políticas contábeis evidenciar os seguintes itens da métrica: definição da vida útil, método de amortização, valor amortizado na DRE e realização do teste de recuperabilidade.

A empresa que obteve o maior nível de evidenciação (100\%) foi a Alupar Investimentos S.A., do setor de Utilidade Pública, sendo que a métrica foi composta por 11 dos 14 itens, sendo que por ter realizado, mas não encontrado perda/reversão no seu teste de recuperabilidade os itens 9,10 e 11 foram desconsiderados na métrica.

Das 75 companhias analisadas, apenas 31 apresentaram um item além do exigido, sendo que as companhias dos setores de Utilidade Pública e Petróleo, Gás e Biocombustíveis evidenciaram um percentual aplicado sobre a receita operacional líquida para pesquisa e desenvolvimento do setor de atuação, conforme determina a legislação, informação presente em empresas de outros setores também, como Natura Cosméticos S.A. (nível de evidenciação do ativo intangível de $63,64 \%$ ) e Totvs S.A. (63,64\%). Das quatro companhias do setor de 
Petróleo, Gás e Biocombustíveis apenas a Petróleo Brasileiro S.A. (84,62\%) informou, enquanto do setor de Utilidade Pública, entre elas a Alupar Investimentos S.A., nove das 18 companhias presentes no estudo que compuseram a carteira informaram.

A Companhia Brasileira de Distribuição (81,82\%) e a Qualicorp S.A. (76,92\%) apresentaram o valor do intangível a pagar, a última ainda informa o compromisso do que planeja adquirir para os próximos anos de software em andamento. E a Companhia Minerva S.A. $(53,85 \%)$ trouxe o ano em que cada ágio foi adquirido e um pequeno histórico de cada.

De acordo com a Tabela 2, o item mais evidenciado, com 96\%, foi o item 13 conciliação do valor inicial e final com as entradas, saídas e baixas, seguido da natureza do intangível com 93,33\%. Sendo que do item 13 as três empresas que não divulgaram as notas explicativas não apresentaram, e o item um, essas três mais a Multiplus S.A. $(45,45 \%)$ e a Companhia de Transmissão de Energia Elétrica Paulista (21,43\%), não apresentaram, sendo que a primeira divide apenas em intangível gerado internamente e outros e a segunda apresenta apenas o valor total de consolidado e controladora.

Tabela 2 - Média do nível de evidenciação por item

\begin{tabular}{c|l|c|c}
\hline Item & Descrição & Atendeu & Média \\
\hline 1 & Natureza do intangível & 70 & 93,33 \\
\hline 2 & Informa vida útil & 43 & 57,33 \\
\hline 3 & Prazo da vida útil definida & 31 & 41,33 \\
\hline 4 & Taxa para amortização & 32 & 42,67 \\
\hline 5 & Método de amortização & 53 & 70,67 \\
\hline 6 & Valor contábil bruto & 57 & 76,00 \\
\hline 7 & Informa amortização acumulada & 57 & 76,00 \\
\hline 8 & Efetuou o teste de recuperabilidade & 66 & 88,00 \\
\hline 9 & Informou valor da perda (caso houve) & 17 & 65,38 \\
\hline 10 & Informou se houve reversão (caso houve) & $2^{2}$ & 18,18 \\
\hline 11 & Evidencia valor perda/reversão na DRE (caso houve) & $18^{3}$ & 24,00 \\
\hline 12 & Evidencia valor amortizado na DRE & 7 & 26,92 \\
\hline 13 & Concilia valor inicial e final - baixa e entradas & 72 & 96,00 \\
\hline 14 & Evidencia além das exigidas na NBC TG 04 (R4) & 31 & 41,33 \\
\hline
\end{tabular}

Fonte: Elaborado pelos autores com base nos dados da pesquisa.

Legenda: 1- 49 empresas receberam "não se aplica". 2 - 64 empresas receberam "não se aplica". 3 - 26 empresas receberam "não se aplica".

Em contrapartida, o item menos evidenciado foi o 10 - informou se houve reversão, com apenas duas das 11 empresas na qual o item se aplicava e um percentual de 18,18 . O segundo foi o item 12 - valor amortizado na DRE, com apenas 18 empresas e um percentual de 24,00. Seguido do item 11 - informa valor da perda na DRE com apenas $26,92 \%$, com apenas 7 de 26 evidenciações, sendo que quando a entidade não divulgou se realizou ou não o teste de recuperabilidade (item 8) foi atribuído " 0 " nos itens que o envolvem (itens 8, 9, 10 e 11).

$\mathrm{Na}$ Tabela 3 é demonstrado que a média do preço da ação utilizada na regressão múltipla é de $\mathrm{R} \$ 26,57$, sendo que o preço máximo foi da Magazine Luiza S.A. de R\$227,99 o que a tornou um outliers na estatística. A média do resultado líquido por ação (RLAC) foi baixa em virtude de 15 empresas apresentarem prejuízo por ação no ano de 2016. O maior valor foi de $\mathrm{R} \$ 30,05$ da Companhia de Transmissão de Energia Elétrica Paulista, e assim como anterior, tornou-se um outliers.

A Magazine Luiza também apresentou o maior patrimônio líquido por ação (PLAC), e por consequência também é um outliers dessa variável. Apenas uma empresa, Gol Linhas Aéreas Inteligentes S.A., apresentou passivo a descoberto, e por consequência apresentou o valor mínimo do patrimônio líquido por ação $(\mathrm{R} \$-0,64)$. 
Tabela 3: Média das variáveis utilizadas na value relevance

\begin{tabular}{l|c|c|c|c}
\hline \multicolumn{1}{c|}{ Variável } & Média & Desvio Padrão & Máximo & Mínimo \\
\hline Preço da ação $-(\mathrm{R} \$)$ & 26,57 & 28,87 & 227,99 & 2,10 \\
\hline RLAC $-(\mathrm{R} \$)$ & 1,55 & 4,08 & 30,05 & $-2,11$ \\
\hline PLAC $-(\mathrm{R} \$)$ & 13,54 & 19,94 & 113,30 & $-0,64$ \\
\hline NEAI $-(\%)$ & 62,93 & 17,25 & 100,00 & 9,09 \\
\hline
\end{tabular}

Fonte: Elaborado pelos autores com base nos dados da pesquisa.

Em relação à influência que o nível de evidenciação exerce sobre o preço das ações foi elaborada dois grupos de regressão, um com toda a amostra (utilizou-se as 75 empresas) e outro sem outliers, compondo o segundo grupo por 67 empresas.

Inicialmente tratar-se-á a amostra composta pelas 75 empresas, visto que mostra um cenário mais realista. A Tabela 4 Painel A mostra que as variáveis de controle RLAC e PLAC preenchem os requisitos do teste $\mathrm{F}$, uma vez que apresenta um p-value inferior a 0,05 , evidenciando que o modelo possui pelo menos um coeficiente da variável diferente de zero, já o teste $\mathrm{T}$, na qual os parâmetros estimados dos coeficientes são estatisticamente significativos, apenas o RLAC apresentou-se significativo a 5\%.

Tabela 4: Regressão entre o preço e lucro líquido por ação e patrimônio líquido por ação

\begin{tabular}{|c|c|c|c|}
\hline \multicolumn{4}{|c|}{ Painel A } \\
\hline Variáveis & Coeficiente & Erro Padrão & Teste T p-value \\
\hline Constante & 15,5703 & 3,2569 & 0,000 \\
\hline RLAC & 1,5699 & 0,1856 & 0,001 \\
\hline PLAC & 0,6320 & 0,9082 & 0,088 \\
\hline \multicolumn{4}{|c|}{ Painel B } \\
\hline Descrição & Valor & Descrição & Valor \\
\hline $\mathrm{R}^{2}$ & 0,3727 & Breush-Pagan (estatística) & 198,79 \\
\hline $\mathrm{R}^{2}$ ajustado & 0,3553 & Breush-Pagan (p-value) & 0,0000 \\
\hline Root MSE & 23,177 & Teste White (estatística) & 62,34 \\
\hline Teste F & 21,39 & Teste White (p-value) & 0,0000 \\
\hline Teste F (p-value) & 0,0000 & Multicolinearidade - VIF & 1,89 \\
\hline Shapiro-Francia ( $\mathrm{p}$-value) & 0,00001 & Número de observações & 75 \\
\hline
\end{tabular}

Fonte: Elaborado pelos autores com base nos dados da pesquisa.

Conforme o Painel A da Tabela 4, quando o resultado líquido por ação é acrescentado em um real ocasiona um aumento de quase 1,57 reais no valor da ação.

Quanto aos pressupostos referentes aos resíduos foram evidenciados na Tabela 4 Painel $\mathrm{B}$, na qual evidenciou a distribuição normal através do teste de Shapiro-Francia um p-value inferior a 0,05 indicando que os resíduos não possuem uma distribuição normal. Em relação à heterocedasticidade, os resíduos apresentam problemas em virtude do p-value do teste de Breush-Pagan e Teste White serem menores que 0,05. Por fim, o teste VIF (fator de inflação variável) verificou se não há correlações elevadas entre as variáveis explicativas, ocasionando na ausência de multicolinearidade, com um valor inferior a quatro (VIF $=1,89$ ).

Ao inserir o nível de evidenciação do ativo intangível (NEAI) na regressão, conforme Equação 3, o poder explicativo passou de 0,3553 (Tabela 4 Painel B) para 0,3809 (Tabela 5 Painel B). Ou seja, o nível de evidenciação, junto com as variáveis de controle, explicam $38,09 \%$ do preço da ação.

Conforme o Painel A da Tabela 5, quando o resultado líquido por ação é acrescentado em um real ocasiona uma majoração de quase 2,06 reais no valor da ação, caso essa adição seja no patrimônio líquido por ação o aumento é de 0,58 reais. Por fim, caso o nível de evidenciação seja incrementado com um por cento, acarretaria num aumento de aproximadamente 0,32 reais no preço da ação.

No que se refere o Painel $\mathrm{B}$ da Tabela 5 , o teste $\mathrm{F}$ foi significativo a $5 \%$, rejeitando a hipótese nula de que todos os coeficientes são iguais à zero. Já em relação à significância das 
variáveis, o teste $T$ também foi significativo, com um p-value inferior a 0,05 , nota-se que a variável de controle PLAC, tornou-se significativa ao modelo após a inclusão do NEAI.

Porém, os pressupostos referentes aos resíduos, apenas a ausência de multicolinearidade foi atingida, visto que o VIF $(1,68)$ foi inferior a quatro. O teste de Shapiro-Francia indica que não há distribuição normal, enquanto os testes de Breush-Pagan e White continuam rejeitando a hipótese nula de que os resíduos são homocedásticos, com intuito de minimizar esse impacto, foram executadas as Equações 2 e 3 (Tabelas 6 e 7) com os dados sem outliers.

Tabela 5: Regressão entre o preço com a variável explicativa

\begin{tabular}{|c|c|c|c|}
\hline \multicolumn{4}{|c|}{ Painel A } \\
\hline Variáveis & Coeficiente & Erro Padrão & Teste T p-value \\
\hline Constante & $-4,4362$ & 10,52 & 0,675 \\
\hline RLAC & 2,059 & 0,9231 & 0,029 \\
\hline PLAC & 0,5793 & 0,1838 & 0,002 \\
\hline NEAI & 31,7159 & 15,8996 & 0,050 \\
\hline \multicolumn{4}{|c|}{ Painel B } \\
\hline Descricão & Valor & Descricão & Valor \\
\hline $\mathrm{R}^{2}$ & 0,406 & Breush-Pagan (estatística) & 200,73 \\
\hline $\mathrm{R}^{2}$ ajustado & 0,3809 & Breush-Pagan (p-value) & 0,0000 \\
\hline Root MSE & 22,712 & Teste White (estatística) & 65,82 \\
\hline Teste F & 16,18 & Teste White (p-value) & 0,0000 \\
\hline Teste F p-value & 0,0000 & VIF & 1,68 \\
\hline Shapiro-Francia (p-value) & 0,00001 & Número de observações & 75 \\
\hline
\end{tabular}

Fonte: Elaborado pelos autores com base nos dados da pesquisa.

Discorrendo, portanto, sobre a amostra sem outliers, primeiramente foram encontradas oito empresas com dados atípicos, sendo oito referentes ao patrimônio líquido por ação (Centrais Elétricas Brasileira S.A., Fibria Celulose S.A., Telefônica Brasil S.A., Cia Paranaense de Energia, Cia de Saneamento de Minas Gerais, Magazine Luiza S.A., Iochpe-Maxion S.A. e Companhia de Transmissão de Energia Elétrica Paulista) e três ao resultado líquido por ação (Fibria Celulose S.A., Magazine Luiza S.A. e Companhia de Transmissão de Energia Elétrica Paulista), sendo que estas foram idênticas aos outliers do PLAC.

O Painel A da Tabela 6 evidencia o output entre o preço da ação e o RLAC e PLAC, em virtude de um p-value inferior a 0,05 para o teste $\mathrm{F}$, indicando que o modelo possui pelo menos um parâmetro diferente de zero. Em contrapartida, o teste $\mathrm{T}$ resultou num p-value superior a $5 \%$ para o PLAC, não sendo estatisticamente significante.

De acordo com o Painel A da Tabela 6, quando o resultado líquido por ação é acrescentado em um real provoca um aumento de quase 6,77 reais no valor da ação, se esse incremento fosse no patrimônio líquido por ação o aumento é de apenas 0,03 reais.

Tabela 6: Regressão entre o preço e lucro líquido por ação e patrimônio líquido por ação sem outliers

\begin{tabular}{cccc}
\hline & & Painel A & Teste T p-value \\
\hline Variáveis & Coeficiente & Erro Padrão & 0,000 \\
Constante & 17,85 & 2,7234 & 0,000 \\
RLAC & 6,7665 & 1,3868 & 0,931 \\
PLAC & 0,0254 & 0,2909 & Valor \\
\hline & & & 1,47 \\
Descricão & Valor & Painel B & 0,2251 \\
$\mathrm{R}^{2}$ & 0,2999 & Descricão & 1,22 \\
$\mathrm{R}^{2}$ ajustado & 0,2781 & Breush-Pagan (estatística) & 0,943 \\
Root MSE & 14,108 & Teste White (estatística) & 1,14 \\
Teste F & 13,71 & Teste White (p-value) & 67 \\
Teste F (p-value) & 0,0000 & VIF & \\
Shapiro-Francia (p-value) & 0,00001 & Número de observações & \\
\hline
\end{tabular}

Fonte: Elaborado pelos autores com base nos dados da pesquisa. 
Conseguinte, pode-se analisar o Painel B da Tabela 6, na qual mostra que a distribuição normal dos resíduos ainda não foi atingida (p-value $<0,05$ no teste Shapiro-Francia), porém a correlação entre os resíduos e cada uma das variáveis explicativa/de controle indica um p-value superior a 5\%, ou seja, os testes de Breush-Pagan e White indicaram que os resíduos são homocedásticos, resultado encontrado no estudo de Abubakar e Abubakar (2015). Quanto à multicolinearidade das variáveis explicativas, assinalam a ausência de correlação entre elas, visto que o teste VIF foi de 1,14, assim como Abubakar e Abubakar (2015).

$\mathrm{O}$ Painel A da Tabela 7 apresenta o acréscimo do NEAI à regressão, o poder explicativo aumentou de 27,81\% (Tabela 6 Painel B) para 30,25\% (Tabela 7 Painel B). Consoante, caso o resultado líquido por ação é incrementado em um real ocasiona um aumento de quase 7,12 reais no valor da ação, se esse aumento fosse no patrimônio líquido por ação o aumento é de apenas 0,10 reais. Caso o nível de evidenciação fosse melhorado em um por cento, resultaria num acréscimo de aproximadamente 0,18 reais no preço da ação.

No tocante ao Painel B da Tabela 7, o teste de White indica que os resíduos são homocedásticos, enquanto a ausência de multicolinearidade é expressa pelo VIF de 1,13, já a distribuição normal dos resíduos não foi atingida, em virtude do Teste de Shapiro-Francia não ser significativo a $5 \%$.

Tabela 7: Regressão entre o preço com a variável explicativa sem outliers

\begin{tabular}{cccc}
\hline & & Painel A & \\
\hline Variáveis & Coeficiente & Erro Padrão & Teste T p-value \\
Constante & 5,1813 & 7,5313 & 0,494 \\
RLAC & 7,1181 & 1,3771 & 0,000 \\
PLAC & 0,0998 & 0,2889 & 0,731 \\
NEAI & 18,7473 & 10,4171 & 0,077 \\
\hline & & & Valor \\
Descrição & Valor & Painel B & 4,39 \\
R $^{2}$ & 0,3342 & Descricão & 0,0361 \\
R $^{2}$ ajustado & 0,3025 & Breush-Pagan (estatística) & 5,38 \\
Root MSE & 13,867 & Teste White (estatística) & 0,8004 \\
Teste F & 10,54 & Teste White (p-value) & 1,13 \\
Teste F p-value & 0,0000 & VIF & 67 \\
Shapiro-Francia (p-value) & 0,00002 & Número de observações & \\
\hline
\end{tabular}

Fonte: Elaborado pelos autores com base nos dados da pesquisa.

Diferente dos outputs apresentados anteriormente, o teste $\mathrm{T}$ da variável explicativa mostrou significância a $10 \%$, ou seja, o p-value de 0,077 , rejeitando que o parâmetro dos coeficientes seja estatisticamente igual à zero, conforme Painel A da Tabela 7.

Os estudos de value relevance do ativo intangível nos seguintes países: Nigéria, Portugal, França, Áustria e Irã; mostram um resultado similar, visto que o ativo intangível evidenciou um poder explicativo significativo ao preço da ação. Os resultados corroboram Kimouche e Rouabhi (2016), na qual evidenciaram que as informações contábeis sobre o ativo intangível possui um incremento na sua relevância. Porém, diferente dos estudos anteriores, que abordaram o valor do ativo intangível, apesar de ser relevante, o nível de evidenciação apresentou um poder explicativo quase nulo, aproximadamente apontou um aumento de 2,5 pontos percentuais. Isso pode ocorrer devido às empresas apresentarem o que lhes foi exigido de acordo com que os gestores consideram material para ser divulgado, ou seja, apesar de obterem um nível médio de evidenciação de $62,93 \%$, estão cumprindo a lei consoante ao que acreditam ser relevante para seus usuários externos.

\section{Considerações Finais}

O intangível de uma empresa nem sempre se resume ao que está contabilizado no ativo, 
pois pode ser evidenciado em suas notas explicativas, inclusive quando gerados internamente podem ser ilustrados em relatórios auxiliares, para que os usuários da informação tenham acesso, tornando assim uma informação essencial para decisão do usuário. Além da sua relevância para o mercado, já que seu valor se ajusta conforme as informações fornecidas.

Nesse contexto, procurou-se verificar a influência do nível de evidenciação do ativo intangível na value relevance de companhias de capital aberto brasileiras. Primeiramente, mensurando e descrevendo o nível de evidenciação do ativo intangível e posteriormente, verificando se há relação entre esse nível e o preço das ações.

Quanto ao nível de evidenciação, a amostra evidenciou em média 62,93\%, tendo uma discrepância significativa entre a maior evidenciação (100\%) e a menor $(9,09 \%)$, devendo as empresas abaixo da média melhorar sua evidenciação, e as entidades no geral, melhorar a divulgação quanto ao teste de recuperabilidade e aos valores na DRE. Devem também informar, caso haja, mais que o mínimo exigido pela NBC TG, visto que apenas 41,33\% (31 empresas) pontuaram nesse quesito, sendo que em 12 empresas a informação foi relativa a um percentual em pesquisa e desenvolvimento do setor exigido em lei.

Em relação ao nível de evidenciação e o preço das ações com outliers, houve significância estatística no modelo, com o poder explicativo de 38,09\%. Já o poder explicativo do nível de evidenciação do ativo intangível sem outliers, mostrou-se inferior (30,25\%), porém atendeu os pressupostos de que a correlação entre os resíduos e cada variável explicativa não pode ser elevada (homocedasticidade), de modo que o modelo seja significativo estatisticamente, de forma que o nível de evidenciação do ativo intangível influencie na value relevance.

O poder explicativo, junto ao fato do nível de evidenciação do ativo intangível está associado ao preço das ações, acarreta ao mercado acionário o dever de relatar em suas notas explicativas o que é proposto pela legislação. Até porque o valor de mercado de uma empresa difere do seu valor contábil, tendo em vista as limitações impostas pelos órgãos reguladores sobre o que pode ser registrado no balanço. Destarte, as empresas que possuírem intangíveis em desenvolvimento, marcas, carteiras de clientes, dentre outros intangíveis, deveriam informar os usuários da informação contábil sobre eles. Inclusive estudos anteriores demonstraram que o valor do intangível é relevante e confiável para o mercado acionário, junto disso está o nível de evidenciação que também se mostra associado ao preço das ações.

Os resultados apresentados se limitam a amostra, por ser não probabilística e conter apenas empresas com ativo intangível superior à zero da carteira de Índice Brasil 100, portanto os resultados não podem ser generalizados para outros períodos. Destaca-se também a limitação relativa ao cálculo do índice de evidenciação do ativo intangível, pois foi elaborada com base exclusivamente na NBC TG 04 R4 (2017) e coletado pelo método qualitativo, possíveis vieses foram evitados em ponderações na métrica para que houvesse um padrão no que considerar divulgado.

Vale enfatizar que as evidências podem ser limitadas também pela situação peculiar que ocorreu no Brasil em 2016, com conflitos políticos, econômicos e escândalos, podendo ter afetado a bolsa de valores.

Para estudos futuros, sugere-se analisar períodos diferentes, bem como amostras setoriais, ou a representatividade do ativo intangível nos ativos da empresa, como também verificar em outros itens das demonstrações financeiras padronizadas como explicam o preço da ação em relação às informações divulgadas.

\section{Referências}

ABUBAKAR, S.; ABUBAKAR, M. Intangible Assets and Value Relevance of Accounting Information of Listed High-Tech Firms in Nigeria. Research Journal Of Finance And 
Accounting, [s.1.], v. 6, n. 11, p.60-79, 2015. Disponível em:

http://iiste.org/Journals/index.php/RJFA/article/view/23354/24180. Acesso em: 06 abr. 2017.

BALL, R.; BROWN, P. An empirical evaluation of accounting income numbers. Journal of accounting research, p. 159-178, 1968.

BALL, R.; BROWN, P.R. Ball e Brown (1968): A retrospectiv. The Accounting Review, v. 89, n. 1, p. 1-26, 2013.

BARTH, M.; BEAVER, W. H.; LANDSMAN, W. R. The relevance of the value relevance literature for financial accounting standard setting: another view. Journal Of Accounting And Economics, [s.1.], v. 31, n. 1-3, p.77-104, set. 2001. Elsevier BV.

http://dx.doi.org/10.1016/s0165-4101(01)00019-2

BATISTA, T. C.; OLIVEIRA, J. F.; MACEDO, M. A. S. Relevância da Informação Contábil para o Mercado Brasileiro de Capitais: Uma Análise Comparativa entre Lucro Líquido, Lucro Abrangente e Fluxo de Caixa Operacional. RACE: Revista de Administração,

Contabilidade e Economia, v. 16, n. 1, p. 381-408, 2017.

BEAVER, W. H. The information content of annual earnings announcements. Journal of accounting research, p. 67-92, 1968.

BM\&FBOVESPA. Ações: A vista. Disponível em:

http://www.bmfbovespa.com.br/pt_br/produtos/listados-a-vista-e-derivativos/renda-variavel/acoes.htm. Acesso em: 23 set. 2016.

COMITÊ de Procedimentos Contábeis. Pronunciamento Técnico CPC 00 R1, de 02 de dezembro de 2011. Estrutura conceitual para elaboração e divulgação de relatório contábilfinanceiro. Disponível em: http://www.cpc.org.br. Acesso em: 11 mai. 2017.

COMITÊ de Pronunciamentos Contábeis. Pronunciamento Técnico CPC 04 R1, de 05 de novembro de 2010. Ativo intangível. Disponível em: http://www.cpc.org.br. Acesso em 23 set 2016.

CONSELHO FEDERAL DE CONTABILIDADE. Resolução NBC TG 04 (R4), de 22 de dezembro de 2017. DOU. Brasília, 2017.

FÁVERO, Luiz Paulo et al (Org.). Métodos Quantitativos com Stata. Rio de Janeiro: Elsevier, 2014.

FERNANDES, E.; SALUSSE, E.; JABOUR, M.. Quanto vale um "direito intangível", 2014. Disponível em: http://www.valor.com.br/legislacao/fio-da-meada/3773804/quantovale-um-direito-intangivel. Acesso em: 27 set. 2016.

FIGO, Anderson. Onde estão e qual o tamanho das maiores Bolsas do mundo? 2016. Disponível em: http://exame.abril.com.br/mercados/noticias/onde-estao-e-qual-o-tamanhodas-maiores-bolsas-do-mundo. Acesso em: 30 set. 2016.

FERREIRA, G. D. et al. Value Relevance De Ativos Intangíveis: Uma Análise Nas Empresas Do Setor De Energia Elétrica Da Bolsa Brasileira. In: USP International Conference In Accounting, 17, 2017, São Paulo. Anais... USP, 2017.

FIGO, A. Onde estão e qual o tamanho das maiores Bolsas do mundo? 2016. Disponível $\mathrm{em}:<$ http://exame.abril.com.br/mercados/noticias/onde-estao-e-qual-o-tamanho-das-maioresbolsas-do-mundo>. Acesso em: 30 set. 2016.

GIBBINS, M.; RICHARDSON, A.; WATERHOUSE, J. The management of corporate financial disclosure: opportunism, ritualism, policies, and processes. Journal of accounting research, p. 121-143, 1990. 
GHAHRAMANIZADY, M.; BEHNAME, M. Intangible Assets Value Relevance; Metals Industry of Tehran Stock Exchange Case Study. Technical Journal Of Engineering And Applied Sciences, [s.1.], v. 0, p.2759-2765, 14 out. 2013. Disponível em:

$<$ http://tjeas.com/wp-content/uploads/2013/10/2759-2765.pdf>. Acesso em: 06 abr. 2017.

GONÇALVES, J. C. et al. Análise do impacto do processo de convergência às normas internacionais de contabilidade no Brasil: um estudo com base na relevância da informação contábil. Revista Universo Contábil, v. 10, n. 3, p. 25-43, 2014. doi:10.4270/ruc.2014318

HADI, Ali S. Identifying multiple outliers in multivariate data. Journal of the Royal Statistical Society. Series B (Methodological), p. 761-771, 1992.

HAIR JUNIOR, J. F. et al. Introdução: Tipos de técnicas multivariadas. In: HAIR JUNIOR, Joseph F. et al. Análise Multivariada de Dados. 6. ed. São Paulo: Bookman, 2009. Cap. 1, p. 33. Tradução de Adonai Schlup Sant'Anna.

HASSAN, M. S.; MOHD-SALEH, N. The value relevance of financial instruments disclosure in Malaysian firms listed in the main board of Bursa Malaysia. International Journal of Economics and Management, v. 4, n. 2, p. 243-270, 2010.

HEALY, P. M.; PALEPU, K. G. Information asymmetry, corporate disclosure, and the capital markets: A review of the empirical disclosure literature. Journal of Accounting and Economics, v. 31, n. 1-3, p. 405-440, 2001.

HENDRIKSEN, E. S; VAN BREDA, M. F. Teoria da Contabilidade. 5. ed. São Paulo: Atlas, 2009.

HOLTHAUSEN, Robert W.; WATTS, Ross L. The relevance of the value-relevance literature for financial accounting standard setting. Journal of accounting and economics, v. 31, n. 13, p. 3-75, 2001.

JI, X.; LU, W. The value relevance and reliability of intangible assets. Asian Review Of Accounting, [s.1.], v. 22, n. 3, p.182-216, 26 ago. 2014. Emerald. http://dx.doi.org/10.1108/ara-10-2013-0064.

KIMOUCHE, B.; ROUABHI, A. The impact of intangibles on the value relevance of accounting information: Evidence from French companies. Intangible Capital, [s.1.], v. 12, n. 2, p.506-529, 2016.

KLANN, R. C.; BEUREN, I. M. Reflexos das divergências entre IFRS e US GAAP na evidenciação contábil. Advances in Scientific and Applied Accounting, v. 3, n. 1, p. 2-40, 2010.

LAMBERT, Richard; LEUZ, Christian; VERRECCHIA, Robert E. Accounting information, disclosure, and the cost of capital. Journal of accounting research, v. 45, n. 2, p. 385-420, 2007.

LOPES A. B.; IUDÍCIBUS, S. Teoria avançada da contabilidade. São Paulo: Atlas, 2004 MACEDO, M. A. S.; MACHADO, M. A. V.; MACHADO, M. R. Análise da relevância da informação contábil no Brasil num contexto de convergência às normas internacionais de contabilidade. Revista Universo Contábil, v. 9, n. 1, p. 65-85, 2013.

MACEDO, M. A. S. et al. Análise do impacto da substituição da Doar pela DFC: um estudo sob a perspectiva do value-relevance. Revista Contabilidade \& Finanças - USP, v. 22, n. 57, art. 5, p. 299-318, 2011.

MALACRIDA, M. J. C.; YAMAMOTO, M. M. Governança corporativa: nível de evidenciação das informações e sua relação com a volatilidade das ações do Ibovespa. 
Revista Contabilidade \& Finanças, v. 17, n. spe, p. 65-79, 2006.

MALKIEL, B. G.; FAMA, E. F.. Efficient Capital Markets: A Review Of Theory And Empirical Work*. The Journal Of Finance, [s.1.], v. 25, n. 2, p.383-417, maio 1970. Wiley. http://dx.doi.org/10.1111/j.1540-6261.1970.tb00518.x.

MARSTON, C. L.; SHRIVES, P. J. The use of disclosure indices in accounting research: a review article. The British Accounting Review, v. 23, n. 3, p. 195-210, 1991.

MARTINS, V. G.; MACHADO, M. A. V.; CALLADO, A. L. C. Análise da aditividade de Value Relevance da DDF e da DVA ao conjunto de demonstrações contábeis: evidências de empresas do mercado de capitais brasileiro. Contabilidade, Gestão e Governança, v. 17, n. 1, p. 75-94, 2014.

MENESES, A. F.; PONTE, V. M. R.; MAPURUNGA, P. V. R. Determinantes do nível de disclosure de ativos intangíveis em empresas brasileiras. BASE - Revista de Administração e Contabilidade da UNISINOS, v. 10, n. 2, p. 142-153, 2013.

MIGUEL, C. Como empreendedores podem valorizar bens intangíveis de uma empresa?

Revista Exame PME, São Paulo, maio 2011. Disponível em:

http://exame.abril.com.br/revista-exame-pme/edicoes/36/noticias/patrimonio-intocavel.

Acesso em: 29 set. 2016.

OLIVEIRA, L.; RODRIGUES, L. L.; CRAIG, R. Intangible assets and value relevance:

Evidence from the Portuguese stock exchange. The British Accounting Review, [s.1.], v. 42, n. 4, p.241-252, dez. 2010. Elsevier BV. http://dx.doi.org/10.1016/j.bar.2010.08.001.

OHLSON, James A. Earnings, book values, and dividends in equity

valuation. Contemporary accounting research, v. 11, n. 2, p. 661-687, 1995.

ÖZER, G.; ÇAM, İ. The Role of Human Capital in Firm Valuation: An Application on BIST. Procedia - Social And Behavioral Sciences, Antalya, v. 235, p.168-177, nov. 2016. Elsevier BV. http://dx.doi.org/10.1016/j.sbspro.2016.11.012.

PEREZ, M. M.; FAMÁ, R. Ativos intangíveis e o desempenho empresarial. Revista Contabilidade \& Finanças, São Paulo, v. 17, n. 40, p.07-24, jan. 2006. Quadrimestral. Disponível em: <http://www.revistas.usp.br/rcf/article/view/34174/36906>. Acesso em: 24 set. 2016.

PINTO, A. F. et al. Value Relevance da Evidenciação de Provisões e Passivos Contingentes. Pensar Contábil, v. 16, n. 61, p. 54-65, 2014.

REZENDE, C. V.; ALMEIDA, N. S.; LEMES, S. Impacto das IFRS na assimetria de informação evidenciada no mercado de capitais brasileiro. Revista de Contabilidade e Organizações, v. 9, n. 24, p. 18-30, 2015.

RITTA, C. O. Evidenciação Contábil de Ativos Intangíveis: um estudo nas empresas brasileiras pertencentes ao Índice Bovespa nos anos de 2006, 2007 e 2008. 2010. 108 f. Dissertação (Mestrado) - Curso de Ciências Contábeis, Universidade Federal de Santa Catarina, Florianópolis, 2010.

SALAZAR, J. N. A.; BENEDICTO, G. C. Contabilidade financeira. Cengage Learning Editores, 2004.

SANTOS, A. C. D.; STAROSKY FILHO, L.; KLANN, R. C. Efeitos do processo de convergência às normas internacionais de contabilidade no value relevance das demonstrações contábeis de organizações brasileiras. Revista Contemporânea de Contabilidade, v. 11, n. 22, p. 95-118, 2014. 
SCHVIRCK, E.; LUNKES, R. J.; GASPARETTO, V. Divulgação de informações por segmento: panorama da aplicação do CPC 22. Revista de Educação e Pesquisa em Contabilidade, v. 7, n. 2, p. 131-146, 2013.

SILVA, A.; SOUZA, T. R.; KLANN, R. C.. A influência dos ativos intangíveis na relevância da informação contábil. Revista Contemporânea de Contabilidade, [s.1.], v. 14, n. 31, p.2645, 3 abr. 2017. Universidade Federal de Santa Catarina (UFSC).

http://dx.doi.org/10.5007/2175-8069.2017v14n31p26

SOUZA, M. M.; BORBA, J. A. Value Relevance do Nível de Disclosure das Combinações de Negócios e do Goodwill Reconhecido nas Companhias de Capital Aberto Brasileiras. Revista Contabilidade \& Finanças - USP, v. 28, n. 73, p. 77-92, 2017.

VERRECCHIA, R. E. Discretionary disclosure. Journal of Accounting And

Economics. Philadelphia, p. 179-194. out. 1983.

VERRECCHIA, Robert E. Essays on disclosure. Journal of accounting and economics, v. 32, n. 1-3, p. 97-180, 2001.

* Artigo apresentado no $7^{\circ}$ Congresso UFSC de Controladoria e Finanças. 